Research Article

\title{
Optimization of Magnesium Alloy Wheel Dynamic Impact Performance
}

\author{
Xin Jiang, ${ }^{1}$ Hai Liu $\left(\mathbb{D},{ }^{2}\right.$ Rui Lyu, ${ }^{1}$ Yoshio Fukushima, ${ }^{1}$ Naoki Kawada, ${ }^{1}$ Zhenglai Zhang, \\ and Dongying Ju $\mathbb{1}^{1}$ \\ ${ }^{1}$ Department of Material Science and Engineering, Saitama Institute of Technology, Fusaiji 1690, Fukaya, \\ Saitama 369-0293, Japan \\ ${ }^{2}$ School of Mechanical Engineering, Hebei University of Technology, Tianjin 300000, China \\ ${ }^{3}$ Zhejiang HuaShuo Technology, Co., Ltd., Ningbo 315000, Zhejiang, China \\ Correspondence should be addressed to Dongying Ju; dyju@sit.ac.jp
}

Received 18 May 2019; Revised 6 August 2019; Accepted 16 August 2019; Published 4 September 2019

Academic Editor: Joon-Hyung Lee

Copyright ( $) 2019$ Xin Jiang et al. This is an open access article distributed under the Creative Commons Attribution License, which permits unrestricted use, distribution, and reproduction in any medium, provided the original work is properly cited.

Designing lightweight and comfortable automotive vehicles is a primary aim of the industry. Lightweight wheel designs can have a negative effect on the dynamic impact performance of the wheel; therefore, striking a balance between these two factors is a key objective in the design of automotive vehicles. Magnesium alloy wheels were investigated as magnesium alloy has damping performance advantages over some metal materials. Damping test methods were designed to establish the damping performance parameters of the magnesium alloy material. A finite element analysis model of magnesium alloy wheels was established with certain boundary conditions and constraints. The applicability of the model was verified by free modal evaluation of the wheel. Dynamic impact simulation analysis of the designed wheels was carried out, and the dynamic speed responses of magnesium alloy wheels under the impact of a dynamic load on the road surface were obtained. Comparison of the dynamic impact performance of magnesium and aluminum alloy wheels with the same structure showed that the magnesium alloy wheel achieved the target weight reduction of 32.3\%; however, the dynamic impact performance was reduced. In order to realize the lightweight design, the dynamic impact performance of the magnesium alloy wheel should not be inferior to that of the aluminum alloy wheel; therefore, the design of the magnesium alloy wheel structure was optimized. The structural design optimization of the magnesium alloy wheel was carried out by defining the structural parameters of the wheel and using the acceleration and shock response of the wheel as the outputs. The optimization of weight reduction and dynamic impact performance of magnesium alloy wheels was achieved. Consequently, the designed magnesium alloy wheel was shown to have improved ride comfort while satisfying wheel structural performance standards and providing lightweight design.

\section{Introduction}

Recently, with the increasingly stringent regulatory requirements for energy conservation and emission reduction, there has been a significant increase in the use of magnesium as a structural material because of the lightness of magnesium alloys. Magnesium alloys are structural materials with favorable properties such as low density, high specific strength, high specific stiffness, good vibration dampening characteristics, and excellent castability and have been extensively studied. The use of magnesium material in cars will increase by $15 \%(\sim 227 \mathrm{~kg})$ by 2020 based on future projections for magnesium $[1,2]$. In addition, magnesium alloys are well-known damping materials [3-6]. Therefore, magnesium alloys are very attractive for application in the automotive industry for the development of lightweight automotive vehicles to meet energy saving and environmental protection requirements.

The finite element method is currently one of the fastest developing and most popular numerical methods used in the aviation, automotive, shipbuilding, manufacturing, and electrotechnics industries [7-10]; many contemporary industrial fields; and also modern technologies supported by computers $[11,12]$. The demand for ride comfort has also 
increased; therefore, numerous studies have focused on its improvement [13-15]. Modal correlation is now a wellestablished discipline, and the finite element method is an equivalent way of assessing modal models and describing the dynamic behavior of a system. Studies have shown that the density of mobile dislocation and dislocation movement influence the damping capacity of magnesium and magnesium alloys, and the mobile dislocation movement under stress dissipates a large amount of the vibration energy, making it an important source of the high damping capacity of magnesium alloy [16-20]. Bae [21] studied a wheel with high damping capacity without compromising its structural stiffness.

In this work, good damping capacity was demonstrated for AZ91 magnesium alloy. Theoretical models were applied, and experimental results showed damping with nonlinearity characteristics. The rational testing and characterization of the damping capacity of AZ91 magnesium alloy carried out in this research demonstrates the damping advantages of magnesium alloys. The favorable damping characteristics of AZ91 magnesium alloy were demonstrated through the comparison of AZ91 magnesium alloy, 6061-T6 aluminum alloy, and SPFH540 steel. The wheel responses for different materials and damping ratios were evaluated. Design optimization is a powerful tool for machinery design and can produce the best blueprint for structural design. In this work, the wheel structure topology optimization method is used to optimize the wheel design to satisfy the lightweight and dynamic impact performance requirements. The structure of the wheel spokes was altered in combination with the characteristics of structural damping to design different wheel structures, and the vibration damping performance was analyzed. Consequently, the designed magnesium alloy wheel was shown to have improved ride comfort while satisfying the requirements of wheel structural performance standards and lightweight design.

\section{Dynamic Impact Theory and Method}

In this study, AZ91 magnesium alloy, 6061-T6 aluminum alloy, and SPFH540 steel were used for material vibration analysis. Analysis and experiments were also carried out to analyze the damping ratio and the material damping mechanism. Three materials were used for the analysis and calculations as listed in Table 1.

The composition of the AZ91 magnesium alloy and 6061 aluminum alloy and their thermomechanical treatment were considered. The thermal properties of AZ91 magnesium alloy were melting temperature, $\sim 533^{\circ} \mathrm{C}$; specific heat capacity, $1020 \mathrm{~J} /(\mathrm{kg} \cdot \mathrm{K})$; and thermal conductivity, $51 \mathrm{~W} /(\mathrm{m} \cdot \mathrm{K})$. The thermal properties of 6061 aluminum alloy were melting temperature, $\sim 585^{\circ} \mathrm{C}$; thermal conductivity, $151-202 \mathrm{~W} /(\mathrm{m} \cdot \mathrm{K})$; and specific heat capacity, $897 \mathrm{~J} /(\mathrm{kg} \cdot \mathrm{K})$. Combined with these material properties we conduct related research [22-27].

Magnesium alloys are light metal materials. The damping of magnesium and AZ91 magnesium alloy at room temperature is primarily dislocation damping. Currently, a classic theory to illustrate the dislocation damping mechanism is the Granato and Lücke dislocation damping theory
[28, 29]. Numerous researchers have tested the damping properties of various magnesium and magnesium alloy materials with different structures (such as porous structure) and have obtained a variety of performances related to damping. The examples also include the damping material for performance research such as vibration and frequency response [30-35]. The performance test data characteristics are essentially in line with the G-L dislocation pinning theory model.

The vibration system can vibrate according to its natural frequency when the object leaves the equilibrium position under the action of external force and no longer requires the role of an external force. This vibration that is not under the action of an external force is known as free vibration. The period of free vibration is called the natural period. The frequency at which vibration is free is called the natural frequency and is determined by the conditions of the vibration system, independent of amplitude. When the frequency of the driving force is equal to the natural frequency of the object, the amplitude reaches the maximum, which is the resonance.

In a damped free vibration system, the vibration equation of the system can be calculated. The forced vibration equation under the simple harmonic excitation of the single degree of freedom system is as follows:

$$
\ddot{m} x+\dot{c} \dot{x}+k x=f(t)
$$

where $f(t)$ is the force acting on the system, $m$ is the mass, $c$ is the viscosity, and $k$ is the spring constant. Performing the Laplace transform on both sides of the above equation gives

$$
m\left(s^{2}+c s+k\right) X(s)=F(s)
$$

where $s=\delta+j w$ is the Laplace transform factor; $X(s)=$ $\int_{0}^{\infty} x(t) e^{-s t} d t$ is the transformation of displacement response; and $F(s)=\int_{0}^{\infty} f(t) e^{-s t} d t$ is the transformation of $f(t)$.

$$
Z(s)=m s^{2}+c s+k
$$

It has a stiffness property known as the system dynamic stiffness. The reciprocal is known as the transfer function. Combined with the above equation, $H(s)$ can be expressed as

$$
\begin{aligned}
& H(s)=\frac{1}{m s^{2}+c s+k}, \\
& H(s)=\frac{X(s)}{F(s)} .
\end{aligned}
$$

For the actual vibration system, the transfer function is the ratio of the vibration system measuring point $x(t)$ and the system incentive point $f(t)$. Using $j \omega$ instead of $s$ does not lead to loss of information useful to the system. Therefore, Fourier transforms are performed on both sides of the equation to obtain

$$
X(w)=H(w) \cdot F(w)
$$

The velocity transfer function and acceleration transfer function of the system are available: 
TABle 1: Properties of aluminum, steel, and magnesium.

\begin{tabular}{|c|c|c|c|c|c|c|}
\hline \multicolumn{2}{|l|}{ Material properties } & \multicolumn{2}{|c|}{$\begin{array}{c}\text { Aluminum } \\
(6061-\mathrm{T} 6)\end{array}$} & \multirow[t]{2}{*}{$\begin{array}{c}\text { Magnesium } \\
(\mathrm{AZ} 91)\end{array}$} & \multicolumn{2}{|r|}{$\begin{array}{c}\text { Steel } \\
\text { (SPFH540) }\end{array}$} \\
\hline \multicolumn{6}{|c|}{ (a) Mechanical properties of aluminum, steel, and magnesium } & \\
\hline Density $\left(\mathrm{kg} / \mathrm{m}^{3}\right)$ & & & 2700 & 1830 & & 7850 \\
\hline Modulus of elasticity (GPa) & & & 69 & 45 & & 210 \\
\hline Poisson ratio & & & 0.33 & 0.35 & & 0.3 \\
\hline Yield strength (GPa) & & & 0.276 & 0.16 & & 0.355 \\
\hline \multicolumn{7}{|c|}{$\begin{array}{l}\text { Material Magnesium (\%) Aluminur } \\
\text { (b) Composition of Magnesium alloy }\end{array}$} \\
\hline Magnesium (AZ91) Remainder & $8.3-9.7$ & $0.35-1.0$ & $0.15-0.5$ & $0.1 \max$ & $0.004 \max$ & $0.3 \max$ \\
\hline $\begin{array}{l}\text { Material Aluminum (\%) } \\
\text { (c) Composition of Aluminum alloy }\end{array}$ & Silicon (\%) & Iron $(\%)$ & Copper $(\%)$ & Magnesium (\%) & Zinc (\%) & Other elements (\%) \\
\hline Aluminum (6061-T6) & $0.4-0.81$ & $0.7 \max$ & $0.15-0.4$ & $0.8-1.2$ & $0.25 \max$ & $0.15 \max$ \\
\hline
\end{tabular}

$$
\begin{aligned}
& H^{V}(w)=\frac{X(w)}{F(w)}=\frac{j w}{k-w^{2} m+j w c}, \\
& H^{A}(w)=\frac{X(w)}{F(w)}=-\frac{w^{2}}{k-w^{2} m+j w c} .
\end{aligned}
$$

The material properties were studied based on the theory related. Combination with the attenuation waveform to obtain vibration characteristics allowed the ratio of the absolute values of two adjacent amplitudes in a half cycle to be calculated. The ratio of the absolute values of two adjacent amplitudes was the waveform attenuation coefficient. Curves of free decay vibration are shown in Figure 1, and the damping ratio $\xi$ can be calculated using the following equation:

$$
\zeta=\frac{1}{2 \pi} \log _{e} \frac{a_{n}}{a_{n+1}} .
$$

The frequency-sweeping method is also used for testing the damping of material, as shown in Figure 2. When the frequency-sweeping method is used for testing the damping of material, a resonance peak appears near the resonance frequency and related parameters can be calculated.

\section{Establishing the Wheel Dynamic Impact Model}

3.1. Wheel Dynamic Impact Model. The wheel spokes, disc, and rim are the main parts of a wheel. When designing wheels, safety and engineering standards must be considered. Design optimization is a powerful tool for machinery design and can establish the best method for structural design. In wheel design and optimization, the lightest weight is the optimal design goal [36-38]. The wheel structure was optimized based on optimization theory. Wheel models are shown in Figure 3.

In order to estimate the damping performance of the wheel, a vibration test was carried out. The use of experimental modal analysis methods to identify modal parameters of mechanical components with complex structures is also important for understanding their dynamic characteristics. It is possible to obtain modal parameters such as the natural frequency of the complex structure in the free state

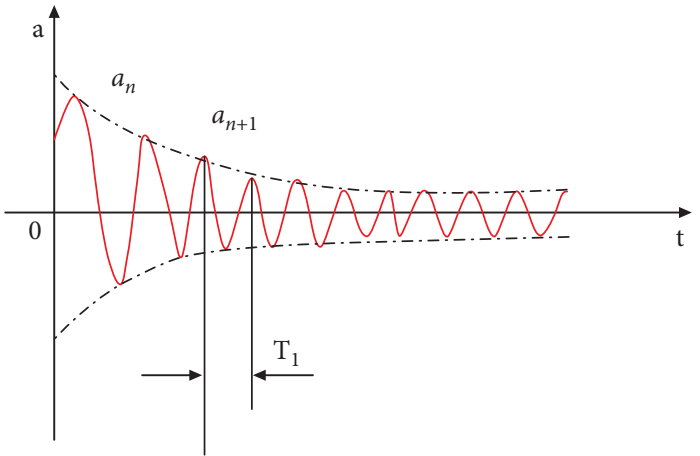

Figure 1: Curves of free decay vibration.

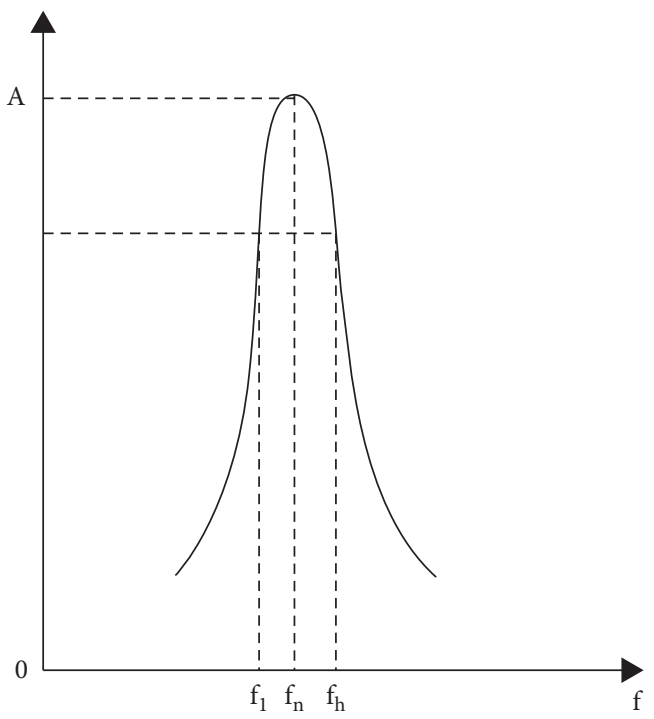

FIgURE 2: Diagram of resonant peak.

and the constrained state, as well as the corresponding mode shapes, and the results of the experimental analysis are extremely accurate. Analysis of the performance of the designed wheel was carried out in addition to the analysis of the materials and the vibration characteristics of the wheel.

3.2. Material Properties. In the damping test, the impact load is imposed on the test specimen and the waveform of the free 


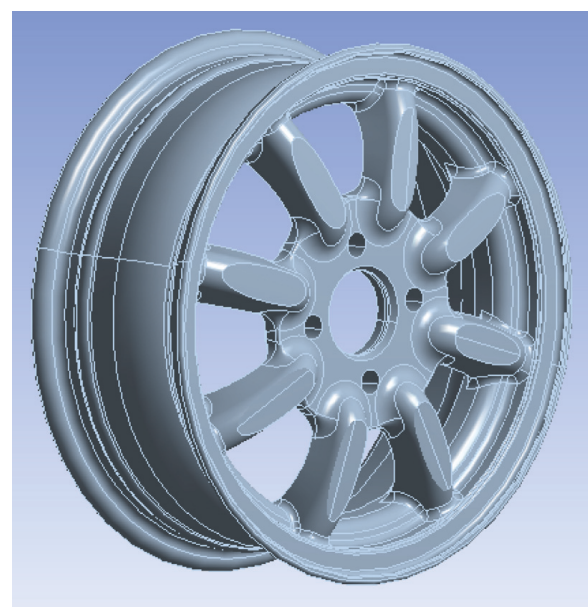

(a)

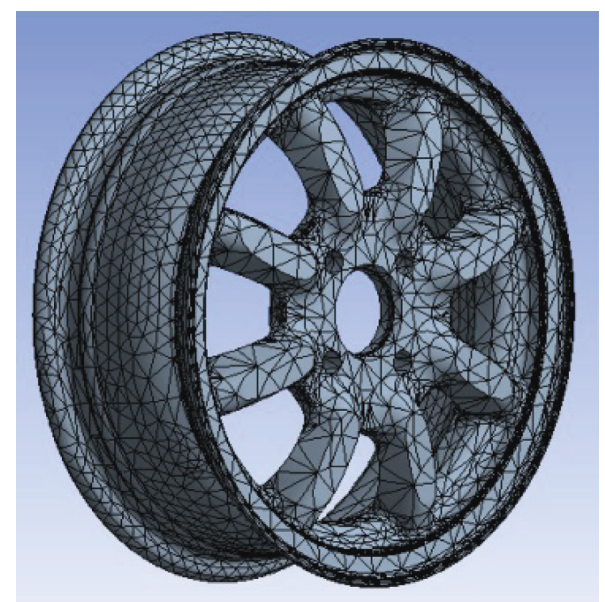

(b)

Figure 3: Magnesium alloy wheel. (a) 3D model. (b) FE model.

decay vibration is obtained. The damping test of the different materials is outlined in Figure 4.

Based on the vibration results data for the damping ratio in Figure 5, and combining the two methods, the damping ratio of the AZ91 magnesium alloy was calculated to be $\sim 0.01081$, the damping ratio of 6061 aluminum alloy was $\sim 0.00695$, and the damping ratio of SPFH540 steel was $\sim 0.00471$. Comparison of the damping ratios shows that the AZ91 magnesium alloy had the best damping characteristics.

3.3. Wheel Dynamic Impact Analysis Model Verification. Model verification is necessary for finite element analysis. A vibration test was carried out in order to estimate the damping performance of the wheel. Free suspension is more repeatable than using a flexible support as it does not introduce the vibration of the supporting gantry or the surrounding experimental environment. The wheel structure as a whole is a symmetrical structure, and when determining the stimulus and response points, it can be selected in a symmetrical manner. An impact hammer and accelerator were used, by hanging the wheel in the air to set the boundary condition free, using LMS for signal acquisition. In order to ensure the accuracy of the test results, the vibration data were collected multiple times for each test and the frequency response function of each test point was obtained using computer software calculations. The vibration test was carried out as shown in Figure 6.

The comparison of the computational results and the experimental results is shown in Table 2.

It can be seen from the mode shape diagram that the mode shape of the wheel is primarily on the wheel rim, the low-order mode shapes were distributed on both sides of the rim, and the high-order mode shapes were distributed in the middle of the rim. As the natural frequency increases, the mode shape of the wheel structure becomes increasingly complex. The error between the computational and experimental results was within $10 \%$, demonstrating the agreement between the model and test. The modal analysis

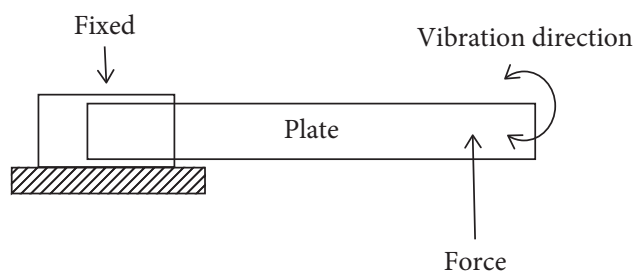

Figure 4: Damping verification plate.

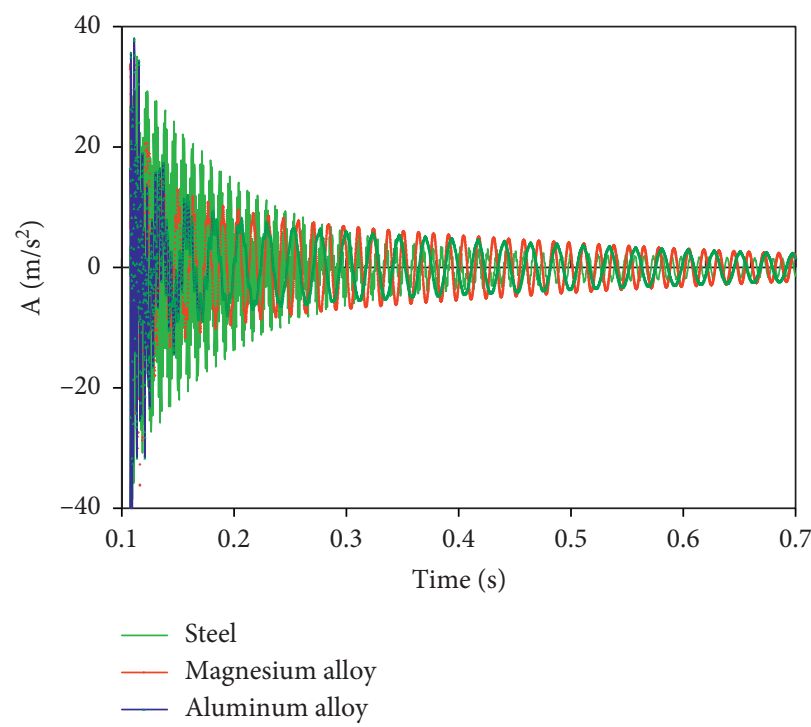

FIGURE 5: Vibration amplitudes of magnesium alloy, aluminum alloy, and steel.

evaluates the natural frequency, mode shape, and other related parameters of the object, which are the essential properties of any object with invariance and stability. Therefore, the finite element model was verified by modal experimental analysis, and the dynamic impact performance comparison of different damping material wheels such as AZ91 magnesium alloy, 6061-T6 aluminum alloy, and SPFH540 steel could be carried out. 


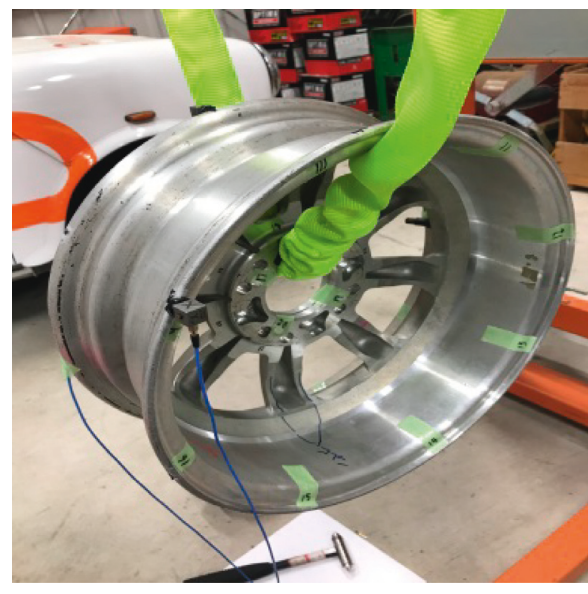

(a)

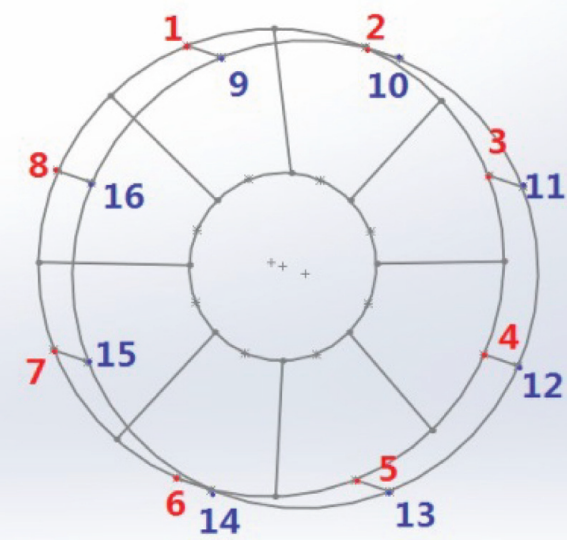

(b)

FIgURE 6: Wheel modal test.

TABLE 2: Comparison of computational and experimental data.

\begin{tabular}{lcccc}
\hline Mode 1 & Mode 2 & Mode 3 & Mode 4 & Mode 5 \\
\hline & Computational & & \\
\hline
\end{tabular}

Experimental
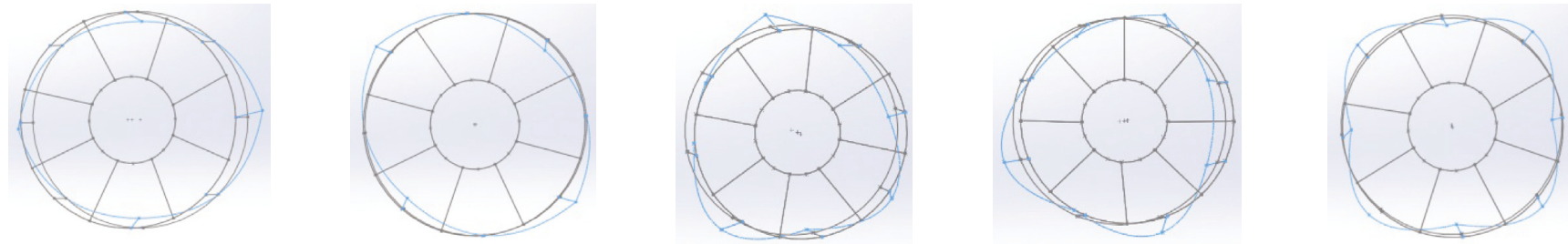

\begin{tabular}{lccc}
\hline Mode 1 & Experimental $(\mathrm{Hz})$ & Computational $(\mathrm{Hz})$ & Error $(\%)$ \\
\hline 1 & 474.5 & 466.1 & 1.8 \\
2 & 480.4 & 494.3 & 2.7 \\
3 & 948.1 & 954.8 & 0.6 \\
4 & 948.5 & 959.1 & 1.1 \\
5 & 1582.8 & 1489.2 & 5.9 \\
\hline
\end{tabular}

\section{Results and Discussion}

4.1. Wheel Dynamic Impact Performance Analysis Results. The vibration response of the AZ91 magnesium alloy and 6061-T6 aluminum alloy was calculated by the frequency response analysis method. Vibration response results of the two materials under the same excitation load can be obtained. This research is primarily focused on the vertical road direction excitation and response. When applying vibration excitation to the center of the wheel with a vertical road surface, the response position is the other side of the vertical road surface where the wheel excitation point is symmetrical. An input load of $1 \mathrm{~N}$ with varying frequency was applied at the wheel application point. Constraints were established on the wheel rotary table. A magnesium alloy wheel and excitation load application in the finite element model of the wheel are shown in Figures 7 and 8, respectively.

Through the comparative analysis of the vibration acceleration and the velocity of the identical position vibration 


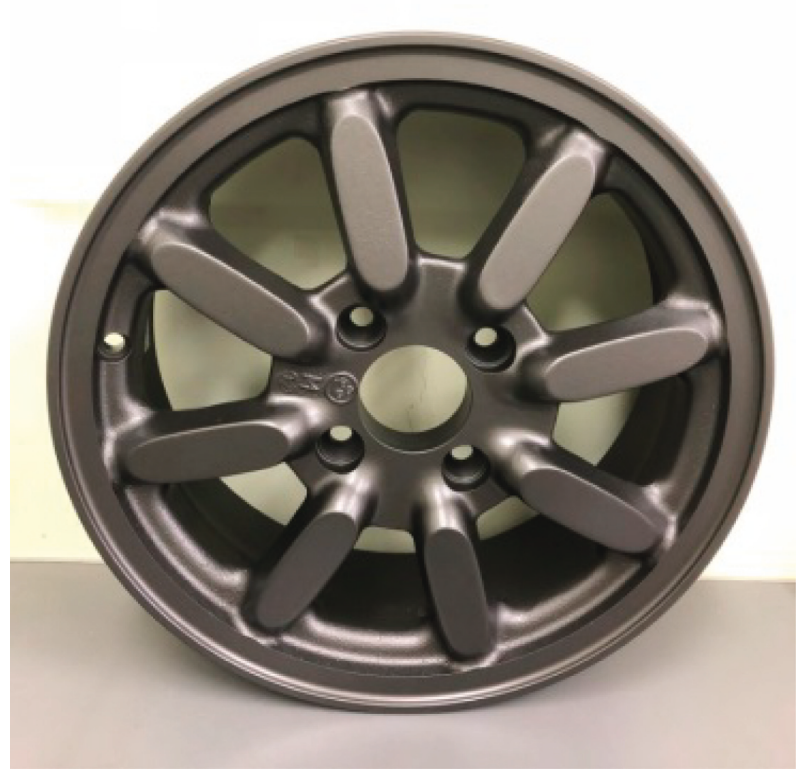

FIgURE 7: Magnesium alloy wheel.

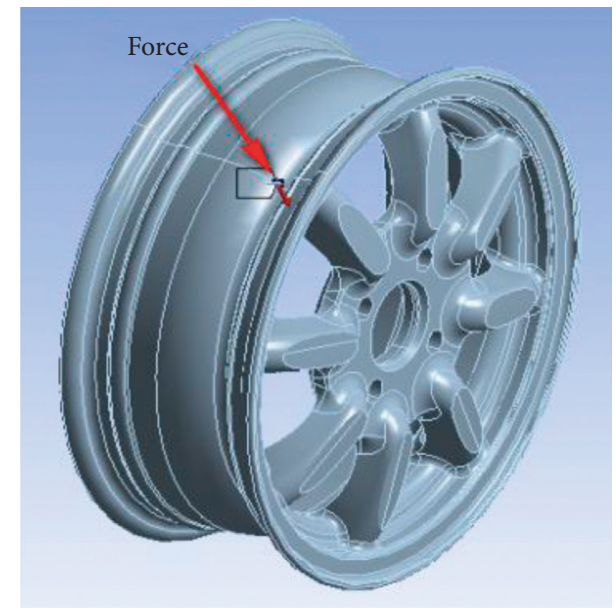

FIgURE 8: Wheel response model.

response points at the center of the wheels made of the two materials, it was determined that the AZ91 magnesium alloy wheel damping and vibration damping performance was good. The wheel response characteristics are shown in Figures 9 and 10.

The spectrograms of the corresponding velocity and acceleration are shown in Figure 10. The frequency responses were analyzed, and the velocity and acceleration results were obtained. The vibration response of the cover of the two materials is mainly determined by the stiffness, damping ratio, and excitation frequency. These results show that the vibration characteristics of the wheel are different under different damping ratios. Comparisons among the different results show the following:

(1) While ensuring lightweight conditions, magnesium alloy wheels give acceleration and velocity changes similar to those for aluminum alloy wheels. The magnesium alloy wheel acceleration peak was $4.6 \mathrm{~m} / \mathrm{s}^{2}$ as shown in Figure 9(a), and the velocity peak was $1.2 \times 10^{-3} \mathrm{~m} / \mathrm{s}$ as shown in Figure 9(b). The magnesium alloy frequency response was in an acceptable range compared with aluminum alloy. The influence of the damping ratio on the wheel was studied based on the damping characteristics.

(2) Using the AZ91 magnesium alloy material with high damping ratio is effective for vibration reduction. The 6061-T6 aluminum alloy acceleration peak was $4.3 \mathrm{~m} / \mathrm{s}^{2}$, and the velocity peak was $1.1 \times 10^{-3} \mathrm{~m} / \mathrm{s}$. Aluminum alloy wheels showed better vibration performance than magnesium alloy wheels with the same structure. Therefore, the optimization of magnesium alloy wheel dynamic impact performance is important.

4.2. Wheel Structure Design Optimization to Improve Structural Damping. The effect of altering the wheel structures was evaluated in combination with the different damping properties of the structures. Based on the relevant theoretical knowledge, the modal and frequency response performance of the bending structure model will change. The offset positions are indicated in Figure 11.

Combined structural design and topology optimization theory suggests that the bending structure tends to perform better in terms of the vibration performance. The simulation analysis of the pedestal support structure shows that the vibration performance improves when the structure changes from Figure 11(a) to Figure 11(b). To optimize the wheel, the spoke design was adjusted. The positions of 1 and 2 were shifted to the left and right along the center. Table 3 shows the size of the adjustments.

The models of the optimized wheel designs combined with structural design criteria and stress-strain related parameters are shown in Figure 12.

Combining the wheel structure damping characteristics and material damping characteristics, the frequency response and vibration-related performance of wheels with different structures are shown in Figures 13 and 14.

From the overall analysis results in Figures 12-14, it was found that the structure of wheel b (Figure 12(b)) reduced both acceleration and velocity effectively, which could result in enhanced ride comfort and a better vibration performance. Replacing 6061-T6 aluminum alloy with the lightweight material AZ91 magnesium alloy resulted in a $76.7 \%$ weight reduction. Based on the results above, considering both the material and structural characteristics,

(1) On the basis of damping characteristics and the wheel structure, vibration performance analyses of different wheel structures were obtained. Acceleration and velocity data of magnesium alloy wheel b are included in Figures 13(a) and 13(b).

(2) The response characteristics of the wheel were obtained by changing the wheel structure. When the wheel structure was a, b, c, d, e, and f in Figure 12, the acceleration peak was $4.6,3.7,4.1,3.9,4.2$, and $4.1 \mathrm{~m} / \mathrm{s}^{2}$, 


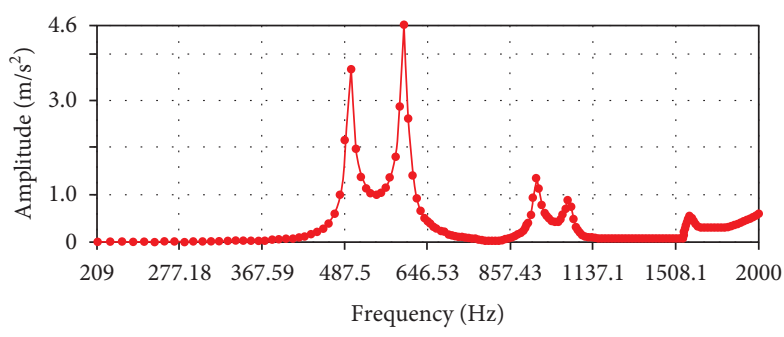

(a)

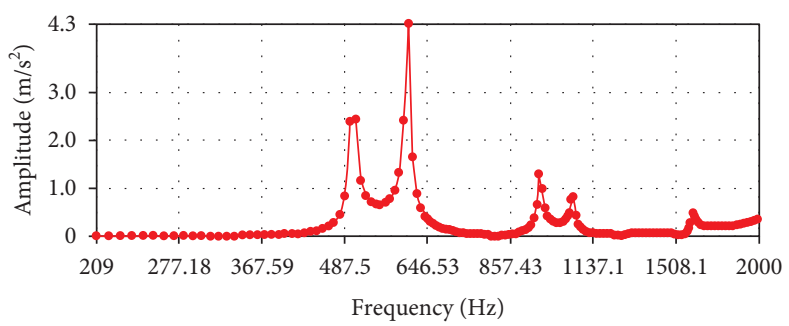

(c)

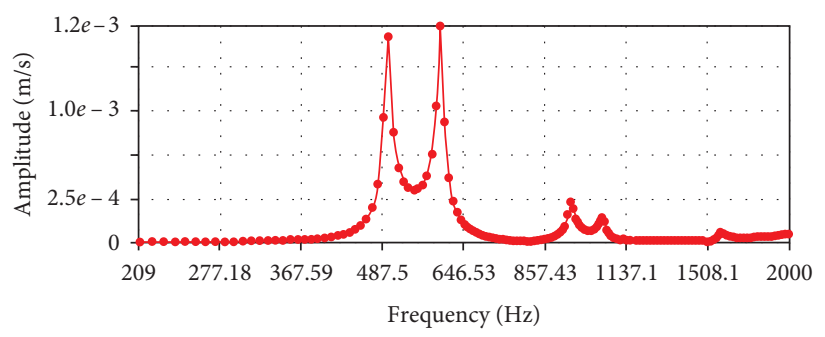

(b)

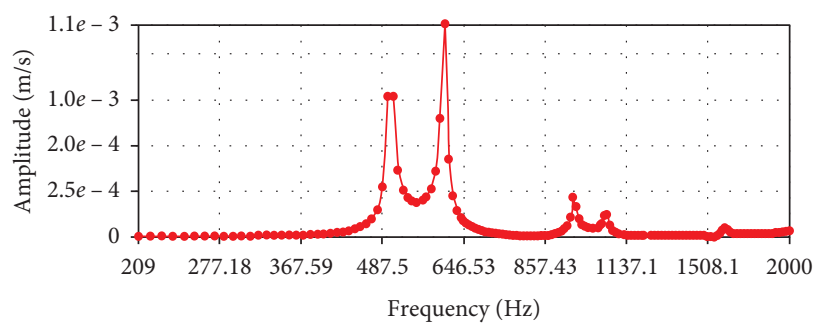

(d)

Figure 9: The results of simulations. (a) Magnesium alloy $a$. (b) Magnesium alloy $v$. (c) Aluminum alloy $a$. (d) Aluminum alloy $v$.

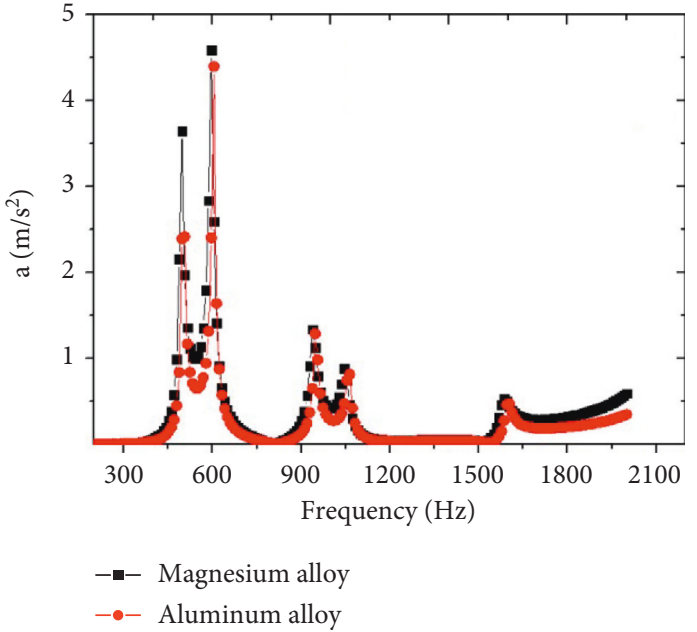

(a)

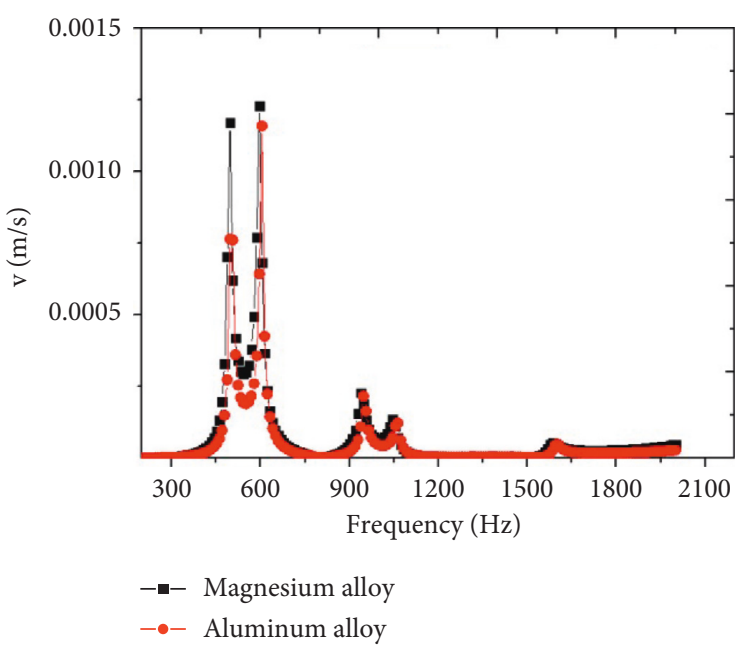

(b)

FIGURE 10: Comparison of wheel response results.

respectively, as shown in Figure 14(a). The velocity of the different damping ratios was $1.2 \times 10^{-3}, 9.7 \times 10^{-4}$, $1.1 \times 10^{-3}, 1.1 \times 10^{-3}, 1.2 \times 10^{-3}$, and $1.2 \times 10^{-3} \mathrm{~m} / \mathrm{s}$, respectively, as shown in Figure 14(b). This demonstrates that the acceleration and velocity performance can be altered by changing the magnesium alloy wheel structure. Magnesium alloy wheel $b$ was the best structure tested in terms of vibration performance.

(3) Using a magnesium alloy structure with bent wheel spokes can effectively reduce vibration. Figure 14(a) shows that, compared with the original magnesium alloy wheel design a, magnesium alloy wheel $b$ reduced the acceleration by $19.5 \%$ and the velocity by $19.1 \%$. When bending of the wheel spokes was continued-wheel c, wheel d, wheel e, and wheel $\mathrm{f}$-the acceleration and velocity rose. Magnesium alloy wheel $\mathrm{b}$, which showed higher damping ratio, is expected to show better vibration performance. Table 4 shows the comparison of wheel performance.

Based on material damping and structural damping, combined with stress and total deformation analysis, the most significant structure was found to be the structure of wheel b (Figure 12(b)). The wheel structure satisfies the static force test requirements, and the magnesium alloy wheel $b$ acceleration peak was $3.7 \mathrm{~m} / \mathrm{s} 2$ and velocity peak was $9.7 \times 10-4 \mathrm{~m} / \mathrm{s}$. Compared with the aluminum alloy wheel, the magnesium alloy wheel $b$ reduced the acceleration by $13.9 \%$ and the velocity by $11.8 \%$. Optimized magnesium alloy wheels were shown to have better vibration performance than aluminum alloy wheels while meeting lightweight design criteria. Therefore, in addition to studying the damping characteristics, it is critical to optimize the weight 


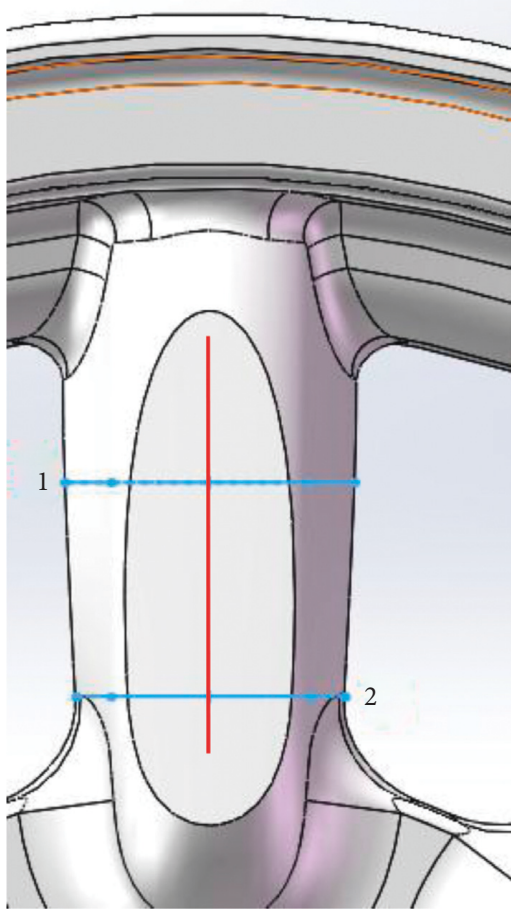

(a)

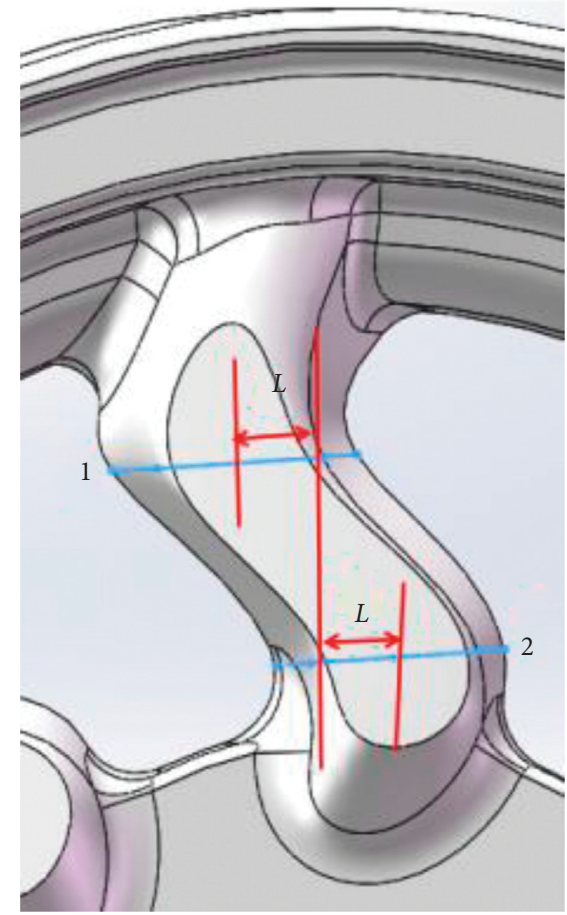

(b)

FIgURE 11: Structural optimization.

TABLE 3: Wheel optimization.

\begin{tabular}{lcccccc}
\hline Name & Wheel a & Wheel b & Wheel c & Wheel d & Wheel e & Wheel $\mathrm{f}$ \\
\hline Size, $L(\mathrm{~mm})$ & 0 & 5 & 7.5 & 10 & 12.5 & 15 \\
\hline
\end{tabular}

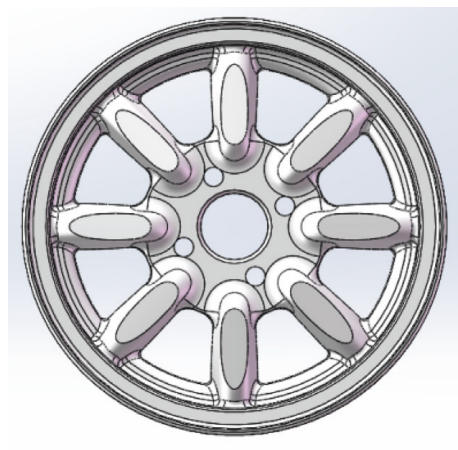

(a)

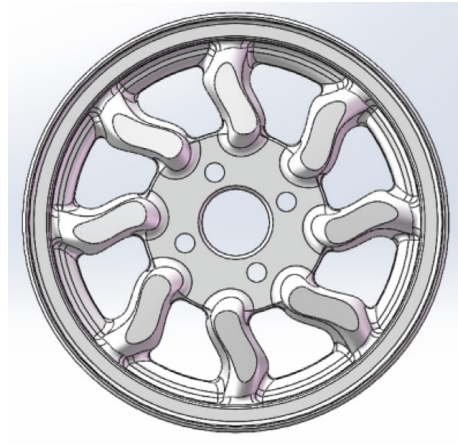

(c)

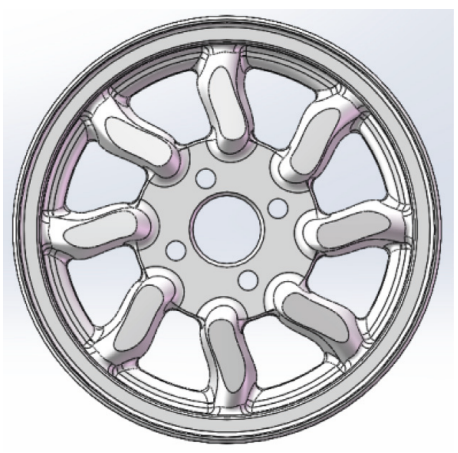

(b)

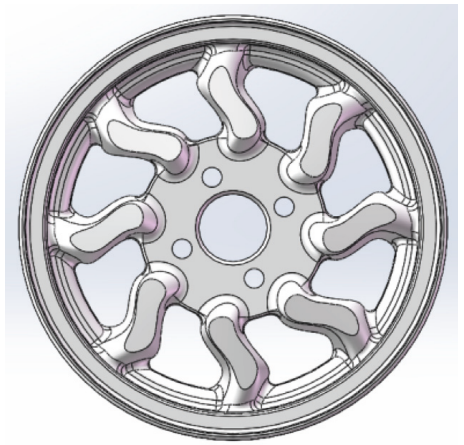

(d)

Figure 12: Continued. 


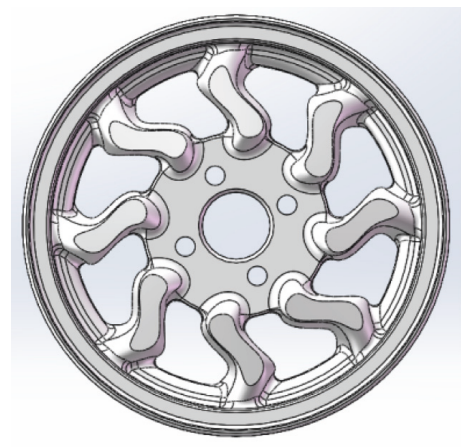

(e)

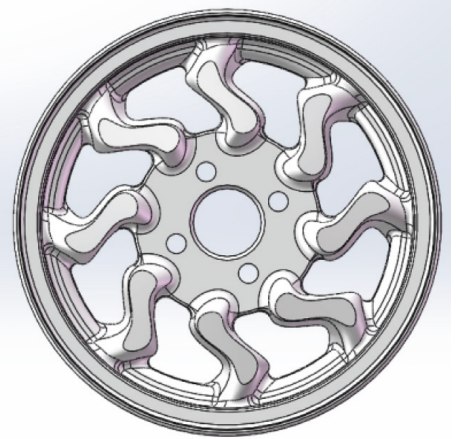

(f)

FIgure 12: Different wheel structures. (a) Wheel a. (b) Wheel b. (c) Wheel c. (d) Wheel d. (e) Wheel e. (f) Wheel f.

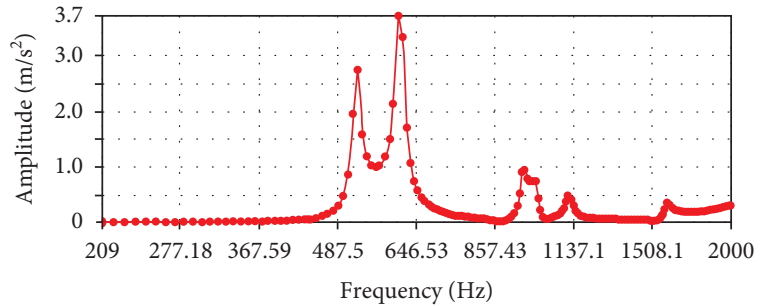

(a)

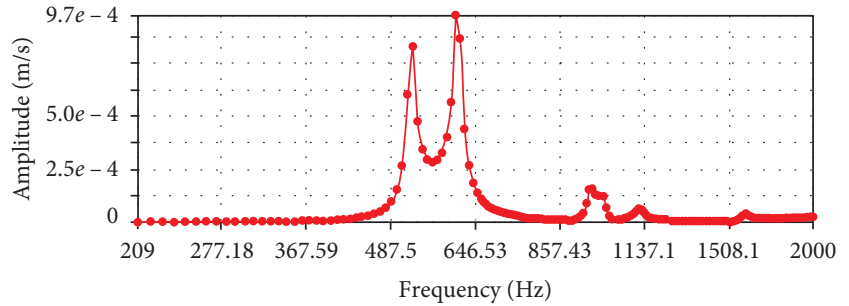

(b)

FIGURE 13: The results of the optimized wheel simulation.

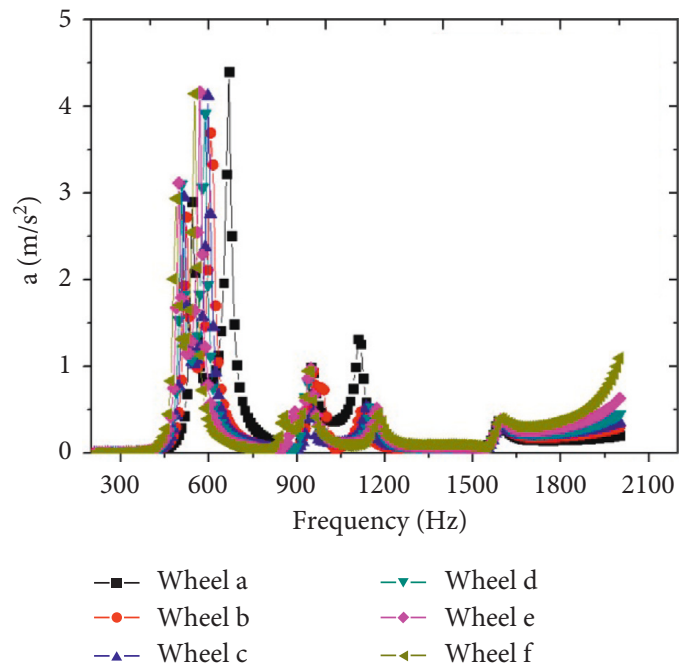

(a)

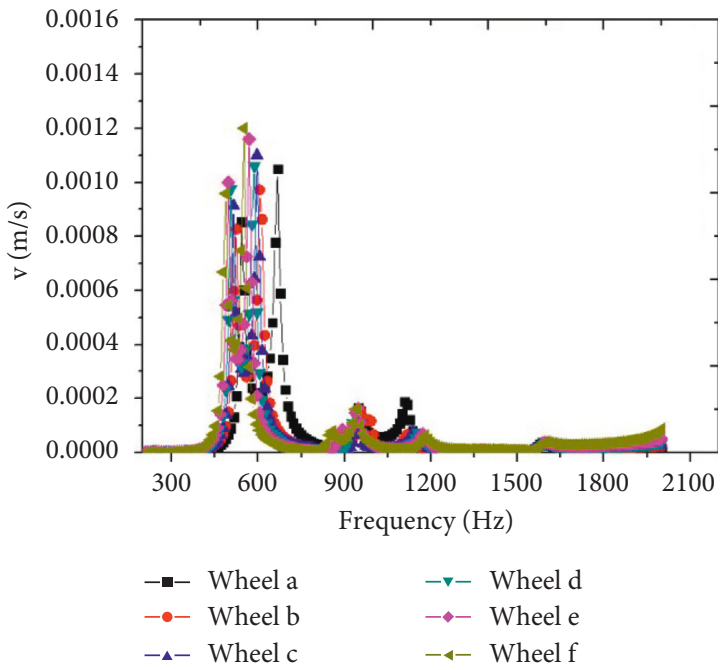

(b)

Figure 14: Continued. 


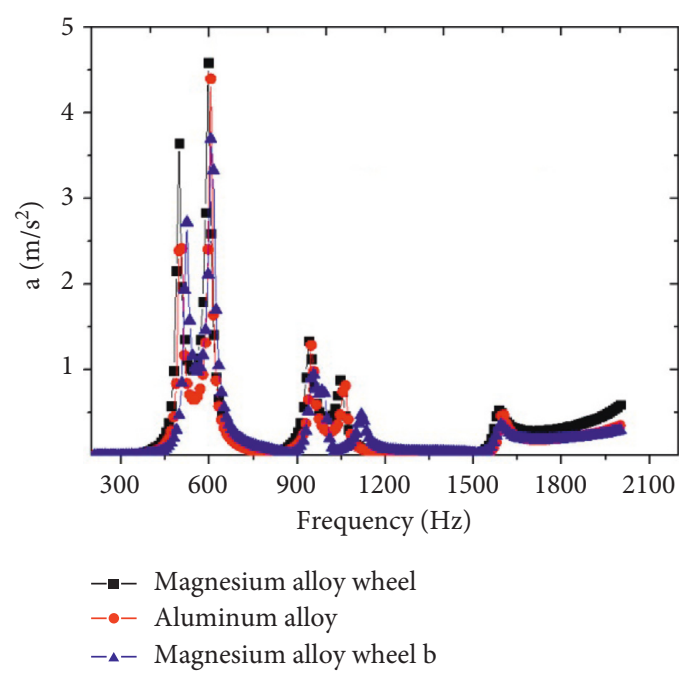

(c)

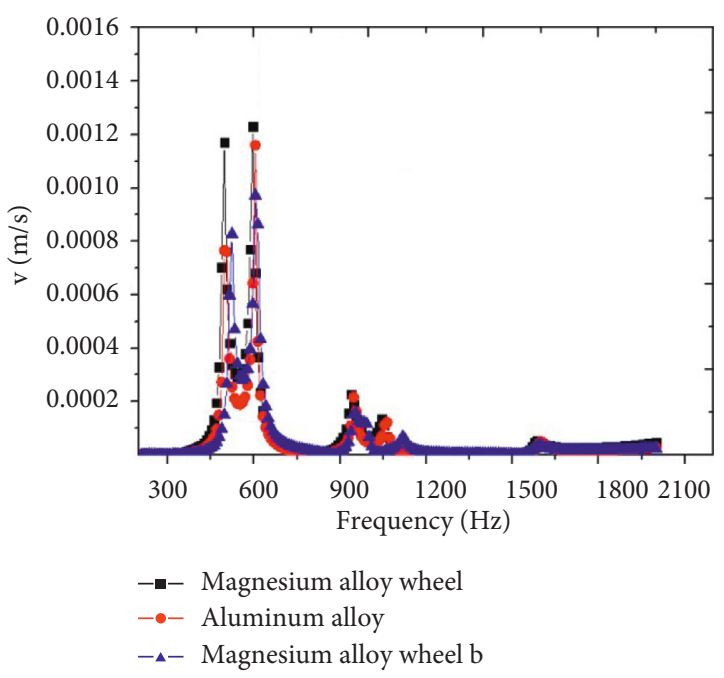

(d)

FIgURE 14: Different wheel analysis results.

TABle 4: Comparison of wheel performance.

\begin{tabular}{|c|c|c|c|c|}
\hline \multicolumn{4}{|c|}{ Wheel performance } & Improvement (\%) \\
\hline \multirow{3}{*}{\multicolumn{2}{|c|}{ Weight $/ \mathrm{kg}$}} & Magnesium alloy & 4.0 & - \\
\hline & & Aluminum alloy & 5.9 & 32.3 \\
\hline & & Steel & 17.2 & 76.7 \\
\hline \multirow{6}{*}{ Vibration } & \multirow{3}{*}{ Acceleration $\left(\mathrm{m} / \mathrm{s}^{2}\right)$} & Aluminum alloy & 4.3 & 13.9 \\
\hline & & Magnesium alloy & 4.6 & 19.5 \\
\hline & & Magnesium alloy (optimized wheel b) & 3.7 & - \\
\hline & \multirow{3}{*}{ Velocity (m/s) } & Aluminum alloy & $1.1 e-3$ & 11.8 \\
\hline & & Magnesium alloy & $1.2 e-3$ & 19.1 \\
\hline & & Magnesium alloy (optimized wheel b) & $9.7 e-4$ & - \\
\hline
\end{tabular}

of magnesium alloy wheels and the vibration reduction performance.

\section{Conclusions}

In order to improve the ride comfort and reduce the weight of automotive vehicles, we designed a magnesium alloy wheel based on structural optimization and dynamic impact performance. In summary of the detailed research, the results of the simulations and experiments led to the following conclusions:

(1) Study of the damping properties of the materials showed favorable damping properties for the magnesium alloy material. Based on the findings of structural optimization and dynamic impact theory, magnesium alloy wheels were designed and manufactured. Compared with the aluminum alloy wheel, the magnesium alloy wheel design can reduce the weight by $32.3 \%$. The designed wheels meet the lightweight requirements in comparison with aluminum wheels, which is expected to increase ride comfort by reducing vibrations.
(2) Damping test methods for the magnesium alloy sample were designed to obtain the damping performance parameters of the magnesium alloy material. Finite element analysis models of the magnesium alloy wheels were established with certain boundary conditions and constraints. The applicability of the model was verified by the free modal experiments on the wheel. Dynamic impact simulation analysis of the designed wheels was carried out, and the dynamic speed response of magnesium alloy wheels under the impact of a dynamic load on the road surface was obtained.

(3) By defining the structural parameters of the magnesium alloy wheel and taking the acceleration and shock response of the wheel as the output, structural design optimization of the wheel was carried out to obtain the optimal magnesium alloy wheel structural parameters. The target of lightweight and high dynamic impact performance magnesium alloy wheels was achieved through optimization. Compared with the aluminum alloy wheel, the optimized magnesium alloy wheel $b$ reduced the acceleration by $13.9 \%$ and the velocity by $11.8 \%$, which is expected to increase 
ride comfort while satisfying the requirements for a lightweight wheel.

Our study opens avenues for the next generation of wheel design. This technique can be applied to a multitude of machine components to enhance various structure vibration performance values. We believe that our analysis can also be used to enhance the response of vibration reduction and lightweight wheel design. We hope that our results will instigate a resurgence of interest in the application of damping material for wheels and motivate future exploration of the effect of other types of structures on wheel vibration behavior.

\section{Data Availability}

The data used to support the findings of this study are included within the article.

\section{Conflicts of Interest}

The authors declare that there are no conflicts of interest regarding the publication of this paper.

\section{Acknowledgments}

This research is based on work supported by the Light Weighting Electric Vehicle Project of Saitama Institute of Technology.

\section{References}

[1] G. S. Cole, "Magnesium vision 2020-a north American automotive strategic vision for magnesium," in Proceedings of the IMA, International Magnesium Association, McLean, VA, USA, April 2007.

[2] V. K. K. Upadhyayula, A. G. Parvatker, A. Baroth, and K. Shanmugam, "Lightweighting and electrification strategies for improving environmental performance of passenger cars in India by 2030: a critical perspective based on life cycle assessment," Journal of Cleaner Production, vol. 209, pp. 1604-1613, 2019.

[3] C. Xianhua, G. Yuxiao, and P. Fusheng, "Research progress in magnesium alloys as functional materials," Rare Metal Materials and Engineering, vol. 45, no. 9, pp. 2269-2274, 2016.

[4] H. J. Jiang, C. Y. Liu, B. Zhang et al., "Simultaneously improving mechanical properties and damping capacity of Al$\mathrm{Mg}-\mathrm{Si}$ alloy through friction stir processing," Materials Characterization, vol. 131, pp. 425-430, 2017.

[5] M. M. Avedesian and H. Baker, "ASM specialty handbook," in Magnesium and Magnesium Alloys, ASM international, Geauga County, Ohio, 1999.

[6] Y. Li and H. Cheng, "Research status and prospect of damping magnesium alloys," Electrical Engineering Materials, vol. 10, no. 5, 2016.

[7] Y. Ding and D. Ju, "Finite element analysis of residual stress in the diffusion zone of $\mathrm{Mg} / \mathrm{Al}$ alloys," Advances in Materials Science and Engineering, vol. 2018, Article ID 1209849, 8 pages, 2018.

[8] T. D. S. Botelho, E. Bayraktar, and G. Inglebert, "Experimental and finite element analysis of spring back in sheet metal forming," International Journal of Computational Materials
Science and Surface Engineering, vol. 1, no. 2, pp. 197-213, 2007.

[9] K. Lenik and D. Wójcicka-Migasiuk, "FEM applications to the analysis of passive solar wall elements," Journal of Achievements in Materials and Manufacturing Engineering, vol. 43, no. 1, pp. 333-340, 2010.

[10] N. Srikanth and M. Gupta, "Estimation of elasto-thermodynamic damping in the $\mathrm{Al} / \mathrm{SiC}$ system using a finite element approach," Acta Materialia, vol. 54, no. 17, pp. 4553-4563, 2006.

[11] H. H. Zhang and S. Q. Zhang, "Extract of stress intensity factors on honeycomb elements by the numerical manifold method," Finite Elements in Analysis and Design, vol. 59, pp. 55-65, 2012.

[12] R. D. Cook, D. S. Malkus, M. E. Plesha et al., Concepts and Applications of Finite Element analysis, Wiley, New York, NY, USA, 1974.

[13] Y. L. Xu and W. H. Guo, "Effects of bridge motion and crosswind on ride comfort of road vehicles," Journal of Wind Engineering and Industrial Aerodynamics, vol. 92, no. 7-8, pp. 641-662, 2004.

[14] D. G. Lee and J. S. Kim, "Computer simulation of the consolidation of fiber-reinforced resin matrix composites," Journal of Materials Processing \& Manufacturing Science (USA), vol. 2, no. 4, pp. 357-372, 1994.

[15] P. E. Uys, P. S. Els, and M. Thoresson, "Suspension settings for optimal ride comfort of off-road vehicles travelling on roads with different roughness and speeds," Journal of Terramechanics, vol. 44, no. 2, pp. 163-175, 2007.

[16] Z. Trojanová, A. Mielczarek, W. Riehemann, and P. Lukáč, "Cyclic bending and the damping behaviour of short fibrereinforced magnesium alloy AZ91," Composites Science and Technology, vol. 66, no. 3-4, pp. 585-590, 2006.

[17] J. Wang, R. Lu, D. Qin, W. Yang, and Z. Wu, "Effect of arcbending deformation on amplitude-dependent damping in pure magnesium," Materials Science and Engineering: A, vol. 615, pp. 296-301, 2014.

[18] L.-M. Wang and R. Richert, "Dynamics of glass-forming liquids. IX. Structural versus dielectric relaxation in monohydroxy alcohols," The Journal of Chemical Physics, vol. 121, no. 22, article 11170, 2004.

[19] A. L. M. Smits, M. Wübbenhorst, P. H. Kruiskamp, J. J. G. van Soest, J. F. G. Vliegenthart, and J. van Turnhout, "Structure evolution in amylopectin/ethylene glycol mixtures by $\mathrm{H}$-bond formation and phase separation studied with dielectric relaxation spectroscopy," The Journal of Physical Chemistry B, vol. 105, no. 24, pp. 5630-5636, 2001.

[20] Y. Yao, L. Chen, and W. Wang, "Damping capacities of $(\mathrm{B} 4 \mathrm{C}+\mathrm{Ti})$ hybrid reinforced $\mathrm{Mg}$ and $\mathrm{AZ91D}$ composites processed by in situ reactive infiltration technique," Acta Metallurgica Sinica, vol. 55, no. 1, pp. 141-148, 2018.

[21] J. H. Bae, K. C. Jung, S. H. Yoo, C. Seung-Hwan, M. Kim, and T. Lim, "Design and fabrication of a metal-composite hybrid wheel with a friction damping layer for enhancement of ride comfort," Composite Structures, vol. 133, pp. 576-584, 2015.

[22] H. Puga, V. Carneiro, J. Barbosa, and V. Vieira, "Effect of ultrasonic treatment in the static and dynamic mechanical behavior of AZ91D Mg alloy," Metals, vol. 5, no. 4, pp. 2210-2221, 2015.

[23] A. Lindemann, J. Schmidt, M. Todte, and T. Zeuner, “Thermal analytical investigations of the magnesium alloys AM 60 and AZ 91 including the melting range," Thermochimica Acta, vol. 382, no. 1-2, pp. 269-275, 2002. 
[24] B. L. Mordike and T. Ebert, "Magnesium: propertiesapplications-potential," Materials Science and Engineering: A, vol. 302, no. 1, pp. 37-45, 2001.

[25] M. Mansourinejad and B. Mirzakhani, "Influence of sequence of cold working and aging treatment on mechanical behaviour of 6061 aluminum alloy," Transactions of Nonferrous Metals Society of China, vol. 22, no. 9, pp. 2072-2079, 2012.

[26] E. Taban, J. E. Gould, and J. C. Lippold, "Characterization of 6061-T6 aluminum alloy to AISI 1018 steel interfaces during joining and thermo-mechanical conditioning," Materials Science and Engineering: A, vol. 527, no. 7-8, pp. 1704-1708, 2010.

[27] Y. Ma, J. E. Jin, and Y. K. Lee, "A repetitive thermomechanical process to produce nano-crystalline in a metastable austenitic steel," Scripta Materialia, vol. 52, no. 12, pp. 1311-1315, 2005.

[28] A. Granato and K. Lücke, "Theory of mechanical damping due to dislocations," Journal of Applied Physics, vol. 27, no. 6, pp. 583-593, 1956.

[29] A. V. Granato and K. Lücke, "Application of dislocation theory to internal friction phenomena at high frequencies," Journal of Applied Physics, vol. 27, no. 7, pp. 789-805, 1956.

[30] H. Watanabe, M. Sugioka, M. Fukusumi, K. Ishikawa, M. Suzuki, and T. Shimizu, "Mechanical and damping properties of fullerene-dispersed AZ91 magnesium alloy composites processed by a powder metallurgy route," $M a$ terials Transactions, vol. 47, no. 4, pp. 999-1007, 2006.

[31] N. L. Wang, P. G. Ji, F. Yin, Q. Dandan, and Q. Yanhuia, "Research of M2052 high damping alloy applied in the vibration reduction of structural component," Journal of Hebei University of Technology, vol. 46, no. 3, 2017.

[32] T. Tian, Z. Yuan, W. Tan, and M. Lin, "Effect of the dynamic evolution of dislocations under cyclic shear stress on damping capacity of AZ61 magnesium alloy," Materials Science and Engineering: A, vol. 710, pp. 343-348, 2018.

[33] D. Kamesh, R. Pandiyan, and A. Ghosal, "Passive vibration isolation of reaction wheel disturbances using a low frequency flexible space platform," Journal of Sound and Vibration, vol. 331, no. 6, pp. 1310-1330, 2012.

[34] P. Davis, D. Cunningham, and J. Harrell, "Advanced $1.5 \mathrm{~Hz}$ passive viscous isolation system," in Proceedings of the 35th Structures, Structural Dynamics, and Materials Conference, Hilton Head, SC, U.S.A., April 1994.

[35] D. Kamesh, R. Pandiyan, and A. Ghosal, "Modeling, design and analysis of low frequency platform for attenuating microvibration in spacecraft," Journal of Sound and Vibration, vol. 329, no. 17, pp. 3431-3450, 2010.

[36] Y. K. Sui and H. L. Ye, Continuum Topology Optimization Methods ICM, Science Press, Beijing, China, 2013.

[37] D. Xiao, H. Zhang, X. Liu, H. Tian, and S. Yingchun, "Novel steel wheel design based on multi-objective topology optimization," Journal of Mechanical Science and Technology, vol. 28, no. 3, pp. 1007-1016, 2014.

[38] J. Liu and Y. Ma, "A survey of manufacturing oriented topology optimization methods," Advances in Engineering Software, vol. 100, pp. 161-175, 2016. 


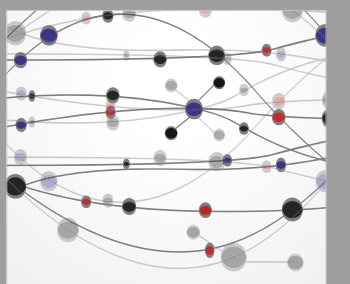

The Scientific World Journal
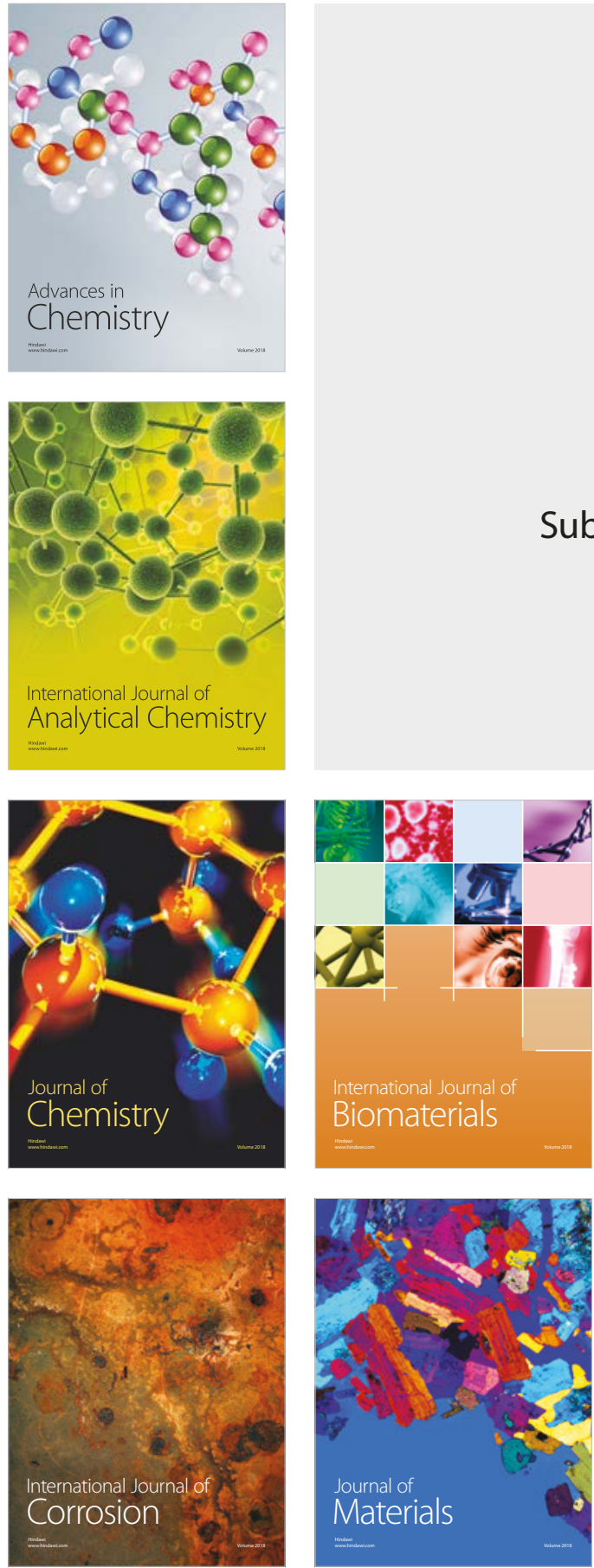

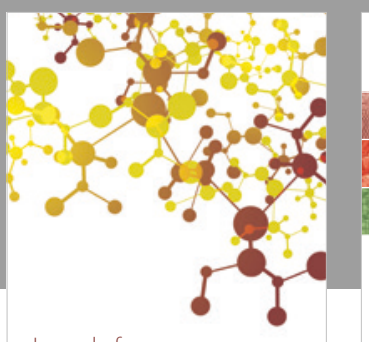

Journal of

Applied Chemistry
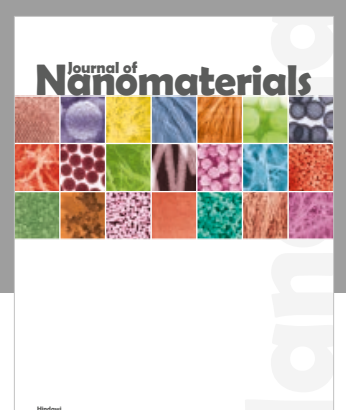

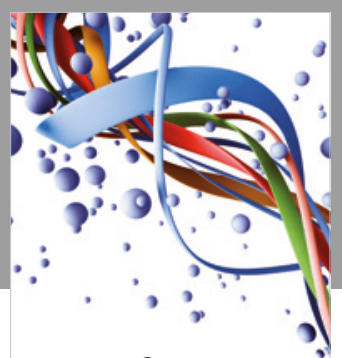

Scientifica

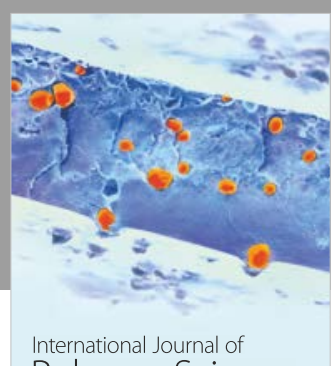

Polymer Science

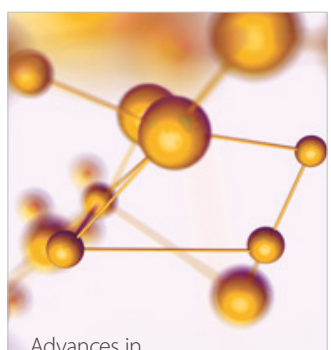

Physical Chemistry
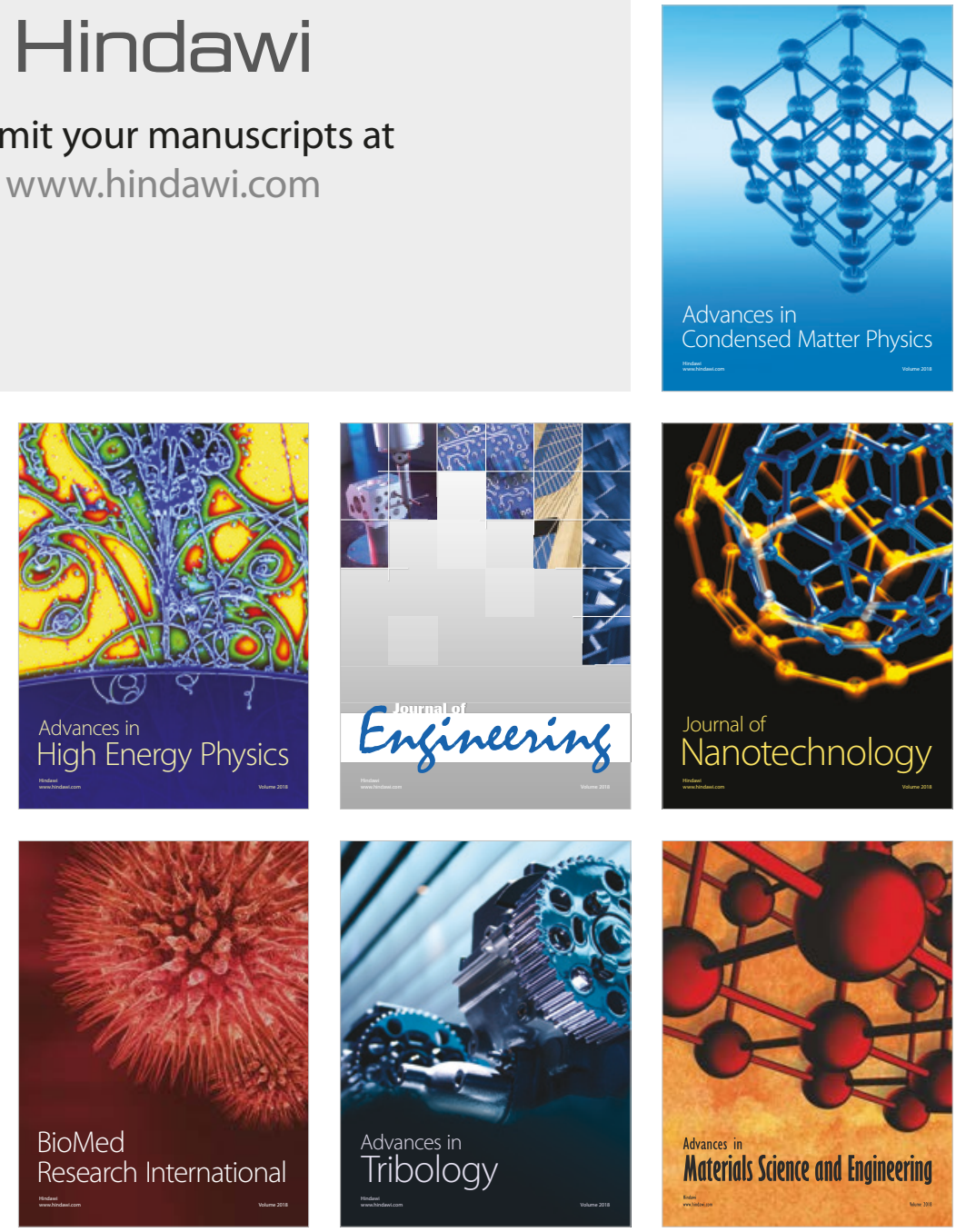